Session 2793

\title{
A Curriculum Collaboration Model: Working with Upper Division Students to Improve a First-Year Program
}

\author{
Blaine Lilly, John Merrill, Omer Masud, Stuart Brand, \\ Michael Hoffmann, Anita Ahuja, Vamsi Ivaturi
}

\author{
The Ohio State University
}

\begin{abstract}
$\underline{\text { Abstract }}$
This paper presents an overview of a quarter-long design-build project in the Fundamentals of Engineering (FE) course sequence, which is part of the First-Year Engineering Program at The Ohio State University (OSU). The current design-build project is discussed along with a justification for the need to institute a replacement. The primary focus of this paper is a unique collaboration model which was developed to address this need. Faculty, staff, and graduate teaching associates from the First-Year Engineering Program joined with the Industrial, Welding and Systems Engineering (IWSE) Department to investigate possible solutions. The paper describes the curriculum research and design methods used by the curriculum team.

The document also discusses the requirements and constraints of the project and presents a detailed timeline of the evaluation and feedback tools implemented. The evaluation and feedback tools used are explained along with sample worksheets. The results of the first quarter are discussed in light of the constraints and requirements of the FE program. Finally, the improvements from the second quarter trials are further explained. This paper will provide clear examples of the project's various cycles, discussion of the planned implementation process, and examples of the final roller coaster design.
\end{abstract}

The collaboration model is reviewed, with experiences gained and future plans presented.

I. Introduction

The Fundamentals of Engineering (FE) course sequence is part of the First-Year Engineering Program at OSU, and is mandatory for all students not enrolled in the Honors equivalent. The FE sequence consists of two courses (ENG 181 and ENG 183), in which students are exposed to Engineering drawing, MATLAB, Excel, hands-on labs, and a quarter-long design-build project involving different fields of engineering. Enrollment in these courses is approximately 1000 students. The current design-build project is entering its third year of full-scale use, and the need to institute a replacement was identified as the result of a curriculum analysis. With up to 162 student teams using lab space and materials in a given quarter, the challenge is to create a replacement that is intellectually challenging while at the same time makes wise and economical use of space and materials. 
A curriculum team of faculty and graduate teaching associates convened in the Summer of 2002 to begin the process. Considering the stages of design, development, and pilot testing, the Winter of 2004 was chosen as the implementation target. Research among various curriculum options resulted in a decision to create a problem-based project in which student teams would design and construct a roller coaster capable of performing specific tasks. Total construction time by students would be reduced by providing a set of interchangeable and interlocking parts leaving students more time to experiment with multiple designs and orientations, and to solve real-world problems (e.g., attaching sensors or wiring to record performance data). However, to ensure a suitable number of design options, the curriculum team sought out collaboration with the Industrial, Welding and Systems Engineering (IWSE) Department to engage upper division students in the concept design and manufacturing.

In Autumn 2002, senior and graduate IWSE students enrolled in an upper division design course were given the task of responding to the specifications and design constraints as set forth by the FE curriculum team. In essence, the FE team is the client and the students were charged with satisfying the client's requirements. After an initial presentation of the problem to the students, the students organized themselves into various teams based on key design issues. Their main objective was the design and construction of suitable parts for the roller coaster track and supporting structure.

Several interim client review sessions were conducted before a final student presentation at the end of the quarter. The curriculum team repeated this process with another group of upper division students in Winter 2003. The outputs of both efforts were a set of working drawings that will be converted into molds for mass production of parts. These parts will go into reusable kits for use by students in the First-Year Engineering Program. This curriculum project is intended to serve as a model of intra-university collaboration that can be replicated elsewhere by programs concerned with creating sustainable and cost-effective design-build projects for largescale first-year engineering programs.

\section{Conventional Curriculum Research and Development at OSU.}

Curriculum research has been an integral part of the curriculum development agenda for the First-Year Engineering Program. ${ }^{2-5,7,8,11-14}$ The research and development of new labs has helped the program stay novel and appealing for the students as well as the faculty. New ideas from various engineering disciplines have been incorporated in labs to engage students' backgrounds and interests. Furthermore, the variety in the lab curriculum exposes freshman students to different disciplines of engineering thus helps them in understanding and choosing the right field of study.

Conventional methods of curriculum research incorporated formation of research and development teams that included graduate teaching associates and faculty members. The teams started by brainstorming project ideas and by defining a set of criteria, which would be used to select the final project. Following the selection of the final project a group of graduate teaching associates were assigned to develop curriculum material as well as the prototype and test equipment. Thus all developmental issues were resolved using the resources of the FE program and in-house expertise. This team verified the feasibility of the project based on which a pilot run 
would be conducted on a small group of students. During the pilot run all aspects of the new lab will be monitored and evaluated by the team. Based on the success of the pilot run the project will be implemented on a larger scale.

\section{Collaboration Model}

In the Summer of 2002 a need for a new design project for ENG 183 was recognized. The existing project is the Conveyor Sorter System, in which students have to develop a sorter system to sort recyclable objects. The students have ten weeks to develop an idea that will efficiently sort recyclable objects, which are placed on a conveyor and correctly count one of the items. This Conveyor Sorter System project improves students' project management and teamwork skills, and also introduces them to concepts in Electrical Engineering, Mechanical Engineering, Product Design, Testing and Reusability and Engineering Ethics. Although the project is very challenging and demanding for the students, the faculty has recognized certain drawbacks in the course material. In evaluating the designs of the student teams the instructional staff has documented the effects of redundancy in design and lack of innovation. The challenging aspect of the design is also diminished as students share and discuss ideas between teams across quarters. This has led to final designs that are very similar and are completed ahead of the scheduled ten-week time period. These drawbacks of the Conveyor Sorter System project have led to the recognition of the fact that the project has to be changed.

To resolve the issue a curriculum research team was formed, which was responsible for the research and development of a new problem-based project for ENG 183. The team started using the conventional curriculum development approach. Some of the important criterions used to short-list the project ideas were as follows:

- Period of instruction (Semester or Quarter)

- The need to integrate lectures and labs

- The need to include several engineering disciplines

- The need to efficiently manage cost and inventory

- The need to develop an efficient evaluation scheme

- The need to incorporate the concepts of team work and project management

Once these criterions were defined, several brainstorming sessions were conducted which led to a number of design ideas. Using the above criteria, all the proposed design ideas were evaluated and ranked. The list was narrowed down to following three probable ideas for a design and build project:

- Monorail

- Roller Coaster

- Security System

During a research meeting the instructional staff proposed a novel approach to the research and development of the projects. Given that the FE program's instructional staff has diverse backgrounds in different disciplines of engineering, and specific product design and production knowledge and expertise was limited, it was realized that the resources at the disposal of the FE project were limited. Thus, it was suggested that IWSE department should be involved in the 
design, research and development of the new project. Recognizing the resources and expertise of the IWSE program such as the machine shop and the specialist personnel along with the necessity of mass production of parts, it was decided that the FE program would approach IWSE for assistance in product (prototype) design. Further research revealed that one of the courses in the IWSE curriculum, ME/ISE 682 had instructional goals which matched the objective of the FE program. The course helps students understand the fundamentals of new product design, and thus could be used to develop the projects for the FE program.

\section{Collaboration with Industrial, Welding, and Systems Engineering (IWSE)}

To explore various design options to manufacture the roller coaster for ENG 183 students the FE curriculum development team approached the IWSE department at OSU. The seniors and graduate students enrolled in an upper division design course in Autumn 2002 were organized into ten project teams. They were assigned the task to design and build a roller coaster track and support structure components, and from those components, build a roller coaster prototype. A second group of IWSE students (eleven project teams) were given the same task in the Winter of 2003 in an effort to improve on existing designs ideas and encourage more innovation. Since the aim was to prototype a product that could be mass-produced for the ENG 183 course, (approximately 200 complete coaster kits), students were able to gain experience in a real world setting. This type of collaboration where the students would design and manufacture parts for a

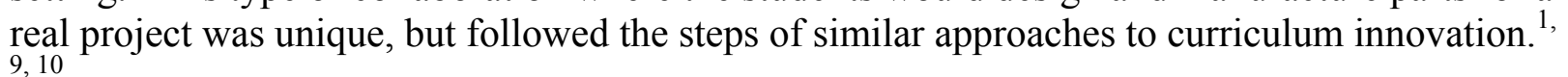

\section{The ME/ISE 682 Course}

ME/ISE 682 is offered by the Mechanical Engineering and Industrial and Systems Engineering Dept at The Ohio State University every quarter. This course is focused on giving the students the fundamentals of new product design. After taking this course the students should be able to apply many of these design tools used by industry to generate new product designs. Because design and manufacturing are so closely connected, the students also look at some of the manufacturing concepts that are current in industry. The class has both lecture and lab periods. The lectures introduce the students to various design concepts. The labs are used for both design exercises and to give the students some extra time to work on the final design project. The project evaluation is a major component of the grade.

\section{Relationship with IWSE}

The relationship of the FE team with the students enrolled in an upper division design course is that of a client to the designers. The ME/ISE 682 students were given project requirements, specifications and constraints by the clients. A presentation was made to the students regarding the requirements and constraints of the clients. The instructor then divided the students into various teams based on key design issues. Within each team there were members responsible for designing the track, the supporting structure and the car. The students were supposed to design and build a roller coaster track and its supporting structure to satisfy the client's needs. The design of the car was not part of the client's requirements but was presented by the instructor to give the students with an opportunity to be innovative. Many client-designer meetings were

\footnotetext{
"Proceedings of the 2003 American Society for Engineering Education Annual Conference \& Exposition Copyright (C) 2003, American Society for Engineering Education"”
} 
conducted to ensure that the designers were on the right track before a final design was selected. The roller coaster prototype was evaluated during the final presentation that the students made at the end of the Autumn 2002 quarter. (The car concept became problematic for the teams and was deleted as a task for the Winter quarter.) The FE team evaluated eleven more designs during the course of the Winter 2003 quarter. The collaboration model turned out to be successful as the FE program (as the client) was able to select several design options for building the track, the supporting structure, and for the mounting of sensors.

\section{Requirements, Constraints and Information Needs for ME/ISE 682 Groups}

Due to time and monetary constraints on the ENG 183 course, the roller coaster needed to be made of standardized, reusable parts that were inexpensive to manufacture, and could rapidly be put together in a variety of configurations as determined by students. The project statement assigned to the ME/ISE 682 students was "Design and build a set of roller coaster track and support structure components, and from those components, build a roller coaster prototype." The aim of the project was to prototype a product that could be mass-produced for the ENG 183 course.

Following are the requirements given to the ME/ISE 682 students:

The track and structure are not separate projects. They should interface to allow a wide variety of successful roller coaster layouts.

○ Track

- Fixed constant width, sized to roll both a 1 " and $3 / 4$ " marble or ball bearing

- Track must not capture the bearing

- Track surface should allow the bearing to roll smoothly, and with minimal rolling friction

- Track must be able to be inclined and banked

- Track features must be able to be resized, and placed at arbitrary locations.

- Vertical loop

○ Any diameter between minimum and maximum

○ Any height, position on the table, or angle of entry

- Allow for non-horizontal entry and exit to the loop

○ Allow for left or right handedness

- Horizontal loop

- Any diameter between minimum and maximum

- Any height, position on the table, or angle of entry

- Allow for left or right handedness

- Bump, dive, and rise

$\circ$ Any height or position on table

- Any radius, down to minimum

$\circ$ Structure

- Must support the track at the level, or at any inclination or bank

- Must support the track features at any location

- Must not flex significantly or slide on the table surface under maximum load 
- Must be collapsible and light

- Other requirements

- There must be points on either the structure or the track for mounting sensors and flags. Each team will be given an example set of sensors and flags.

- All parts, when disassembled, must fit in the standard flip top storage box. Each team will be given a box to store their parts in.

- The coaster parts must be simple enough to allow assembly and disassembly in a maximum of 30 minutes each

- Mass production

- Small number of unique parts

- Interchangeable parts

- Modular design, allowing many coaster configurations from simple parts

- Parts preferably suitable for injection molding

- Inexpensive parts

- Build a prototype for the coaster. (Prototyping requirements are presented in the following section)

PROTOTYPE requirements for ME/ISE 682 projects

- The student teams should build an open loop roller coaster prototype that contains the following features.

- Vertical loop

- Horizontal loop

- Bump

- Dive

- Rise

- There should be at least a 12 inch horizontal track piece in the prototype.

- Length of run should be at least $25 \mathrm{ft}$.

- The roller coaster must fit on the lab table top, inside a space that is 5' long, 4' wide, and 5 ' high. A test structure will be provided to check these dimensions.

- The disassembled coaster must fit in a closed standard flip top storage box.

- At the final coaster operational check, the coaster must be assembled and disassembled in less than 30 minutes each. (Timed)

- The prototype coaster must be capable of running 1 " and $3 / 4$ " ball bearing, with successive trials.

- The bearing will trip a flag mounted to the track

- The bearing will trigger a sensor mounted to the track

- A sensor monitoring circuit will be provided to verify this

- The bearing will drop in a cup at the end of the run, slowly enough to prevent tipping.

Following were the reporting requirements and information needs for the ME/IWSE student groups.

○ Project Notebook 
- House of Quality at all stages

- Self evaluation against specific engineering criteria

- Sample parts for inspection

- Electronic copies of all documentation, on $\mathrm{CD}$, including scans of any hand drawn sketches

○ Basic engineering calculations - refer to Physics 131 texts

$\circ$ Poster, written and oral presentations

Using feedback from the first quarter trial the FE team changed the timeline for the design evaluation meetings to further improve the collaboration effort. In the first trial quarter, the ME/ISE 682 student teams were evaluated twice. In an effort to further improve collaboration and incorporate more feedback into the design process, the ME/ISE 682 student teams in the second trial quarter were evaluated on a much more frequent basis. Following is the timeline for the design evaluation meetings for the second trial quarter.

○ Week 1

○ Week 4

- Project assigned

- Brainstorming results

- Preliminary design sketches of parts and prototype coaster

- Examples of material selection

- Engineering calculations

- Project Notebook check

- House of Quality

- Brainstorming sketches and descriptions

- Preliminary sketches and descriptions

- Engineering calculations

○ Week 6

- Receipts

- Prototype section of track

- Prototype support structure

- Project Notebook check

- House of Quality

- Updated drawings of track \& support structure

- Receipts

○ Week 7

- There would be no design evaluation meeting during this week but the following tasks should be completed.

- Finalized track designs

- Finalized support structure designs

○ Week 8

- First coaster operational check

- Demonstrate track and support structure attached, through loop

- Project Notebook Check

- House of Quality 
- Final part drawings

- Sample track design drawings, start/stop mechanism drawings

- Receipts

○ Week 10 (Final Presentations)

- Timed setup \& teardown

- Track dimension check

- Final coaster operational check

- Oral presentation, PowerPoint \& poster

- Description

- House of Quality

- Self Evaluation

- Lessons learned

- Sample parts available

- Turn in project notebook

- Turn in final written report

\section{Evaluations / Feedback}

The designs of the ME/ISE 682 student teams in Autumn 2002 and Winter 2003 were evaluated using the following three tools.

1. Design Evaluation Worksheet (DEW)

2. Debriefing Meetings

3. Detailed Written Evaluation

The Design Evaluation Worksheet (DEW) lists the constraints and requirements for each of the student teams. Each constraint is then evaluated based on a weighted scale of importance. The weights for each of the constraints were decided by the importance specified by the FE project team. The worksheet computed numerical values for each team depending on the efficiency of the design and the fulfillment of the design criterion. The ME/IWSE 682 student teams were introduced to the evaluation worksheet and were given feedback during and after each design evaluation meeting. DEW was a tool used by the FE team to quantitatively evaluate the performance of the ME/IWSE 682 student teams and thus provide feedback in an effort to improve collaboration. One of the important criteria for judging the final design prototypes was assembly and disassembly time. The assembly and disassembly time weight was twelve percent of the total points allotted to each team. The score was computed by scaling to a thirty minute cutoff time. If student teams took longer than thirty minutes they lost points, up to a sixty minute maximum scale. Conversely, teams gained points if their assembly time was less than the thirty minute cutoff, but only up to a fifteen minute minimum. Please refer to Exhibit 1 for a sample Design Evaluation Worksheet.

Additionally, student teams were evaluated on their designs during debriefing sessions, which took place after each design evaluation meeting. Finally, detailed written evaluations were also provided to the ME/IWSE students in an effort to enhance the feedback process. A summary of comments and evaluations was made available to each team, along with suggestions and questions. 
The ME/IWSE 682 students were introduced to concepts such as "The House of Quality" in their coursework in order to better understand the perspective and requirements of the clients (FE team). The "House of Quality" is a standard tool widely used in industry to match customer needs with engineering specifications. ${ }^{6}$ It gives the design team a "snapshot" of the entire project, and provides a means to ensure that all customer needs are met. The roof of the "House" also shows potential tradeoffs and synergies between specifications. The students used the House of Quality to display how the defined product specifications optimize or sub-optimize each other. Refer to Exhibit 2 for a sample House of Quality.

\section{Results}

The results of the initial-collaboration between the FE program and the IWSE department are noteworthy. At the end of the first quarter trial, the FE program was presented with nine different prototype systems by the ME/ISE 682 student teams. The working models of the prototypes had innovative designs ideas, which were successfully implemented by some teams. During the final presentations certain design implementations demonstrated a fully functional roller coaster track and structure. The final prototypes also provided the FE team with insight into the limitations of the requirements and constraints that were imposed on the ME/ISE 682 student teams. These evaluations led to further discussion among the FE team, which was then able to narrow down specifications further and define the criteria in a much more concise and specific manner. Some student teams were unable to demonstrate a complete working prototype. Although the FE program could not utilize a complete prototype from a single design the FE team was able to pick and choose features and ideas from different prototypes. These ideas could be incorporated together and implemented efficiently to develop a working Roller Coaster prototype. These ideas were also used to improve specifications, requirements and design innovation for the second trial quarter teams. The second quarter trial provided the FE team with eleven more design options which were improvements in innovation as well as functionality. The frequent evaluation meetings and continuous feedback helped improve the design process and in turn offered more practical design options. Two examples of a student-designed track and structure are illustrated in Exhibit 3. An example of a student-designed mounting bracket (for track and sensor) is illustrated in Exhibit 4.

\section{Improvements}

The improvements made to the collaboration model as well as the design process were as follows:

- The frequency of the design evaluation meetings was increased in an effort to collaborate more closely and to provide immediate feedback to the ME/ISE 682 student teams.

- The DEW was developed in order to evaluate designs on a quantitative basis and give extensive feedback.

- Project reporting requirements were imposed in order to receive complete and accurate documentation.

- Criteria such as length of run and a 12 inch straight track were added to the requirements in order to better evaluate the design features. 
- The teams in the second quarter trial were exposed to shortcomings of the first quarter ME/ISE 682 student teams in an effort to decrease the learning curve and thus acquire more innovative designs.

\section{ME/ISE 682 fits FE course timeline}

As a result of the efforts by the ME/ISE 682 students of Autumn 2002, the FE team revised the requirements and constraints for use by the students of ME/ISE 682 in Winter 2003. In the Winter and Spring quarters the FE team is developing the lab material for the project and conducting client meetings with the ME/ISE 682 students. Some graduate students as a part of their independent studies will do the mass-production of parts in Spring 2003. A set of working drawings will be made and molds will be created for injection molding for mass-production of parts. These parts will be placed in reusable kits ready for use by the students enrolled in the FE course as a pilot in Summer 2004 (72 students in 18 teams). Full implementation of the roller coaster project will be implemented full-scale in the FE course (ENG 183) in Winter 2004.

\section{Conclusion}

The FE curriculum development team has been working on the development of the project to design and build the roller coaster since Summer 2002. Collaboration with IWSE began in Autumn 2002. The collaboration provided valuable information towards the creation of unique approach to curriculum development. The innovation and expertise of the IWSE department was invaluable and helped the FE program in the overall curriculum development. The student presentations and working prototypes presented the FE team with information that was used to further improve the second quarter trials. The expectations for the second trial were high as both the clients and the designers had been exposed to experimentation since the first quarter trial. The designs developed in the second quarter were working functional prototypes and presented the FE team with additional options from which to choose.

The final prototype design will be refined in March-April of 2003 with limited production planned for late Spring 2003. The pilot run is expected to run in the Summer of 2003.

Curriculum materials will be finalized in the Autumn along with mass production of parts for full implementation in Winter 2004.

Bibliography

1. Crawford, P., Little, M., 2002, “Collaboration Among Educators for True Innovative Programming," Journal of Teacher Education and Special Education, 25(3):320-324.

2. Duerden, S., Graham, J.M., Garland, J., Doak, B., McCarter, J., Roedel, R.J., Evans, D.L., Williams, P., 1997, "Scaling Up Arizona State University's First-Year Integrated Program in Engineering: Problems and Solutions," Proceedings of the Frontiers in Education Conference.

3. Frair, K., 1995, "An Integrated First Year Curriculum at the University of Alabama: Problems and Solutions," Proceedings of the Frontiers in Education Conference.

4. Fromm E., Quinn R.G., 1989, "An Experiment to Enhance the Educational Experience of Engineering Students," Journal of Engineering Education, pp. 424-429, April.

5. Froyd, J.E., 1995, "Integrated, First-Year Curriculum in Science, Engineering, and Mathematics - A Ten-Year Process," Proceedings of the Frontiers in Education Conference. 
6. Hauser, J.R., Clausing, D., 1988, “The House of Quality," Harvard Business Review, pp 63, April-May.

7. Pendergrass, N.A., Laoulache, R.N., Dowd, J.P., Kowalczyk, R.E., 1998, "Efficient Development and Implementation of an Integrated First Year Engineering Curriculum," Proceedings of the Frontiers in Education Conference.

8. Pendergrass, N.A., Kowalczyk, R.E., Dowd, J.P., Laoulache, R.N., Nelles, W., Golen, J.A., Fowler, E., 2001, "Improving First-Year Engineering Education," Journal of Engineering Education, 90:1, 33-41.

9. Schroeder, C. ACPA Higher Education Trends for the Next Century. "Collaboration and Partnerships." 19 March 2003, http://www.acpa.nche.edu/seniorscholars/trends/trends7.htm

10. Welch, M. (1998). Collaboration: Staying on the Bandwagon. Journal of Teacher Education, 49(1): 26-37.

11. Winkel, B., Froyd, J.E., 1988, "A New Integrated First-Year Core Curriculum in Engineering, Mathematics, and Science: A Proposal," Proceedings of the Frontiers in Education Conference.

12. Winkel, B., Froyd, J.E., 1989, "An Integrated First-Year Engineering Curriculum," Proceedings of the ASEE Annual Conference.

13. Quinn, R. G., "Drexel's E4 Program: A Different Professional Experience for Engineering Students and Faculty," Journal of Engineering Education, Vol. 82, No.4, 1993, pp. 196-202.

14. Foundation Coalition: First-Year Curriculum Page. National Science Foundation. 12 March 2003, $<$ http://www.foundationcoalition.org/home/keycomponents/firstyearcurriculum.html $>$

BLAINE W. LILLY is an Assistant Professor at Ohio State University (OSU), with a joint appointment in the departments of Industrial, Welding, and Systems Engineering and Mechanical Engineering. Before joining Ohio State, he worked as a tool and die maker at General Motors Corporation.

JOHN A. MERRILL is the Director for the First-Year Engineering Program at The Ohio State University (OSU). His current responsibilities include operations, faculty recruiting, curriculum development, and program assessment. Dr. Merrill received his Ph.D. in Instructional Design and Technology from OSU in 1985, and has an extensive background in public education, corporate training, and contract research.

OMER MASUD is a Graduate Teaching Associate for the First-Year Engineering Program at The Ohio State University College of Engineering (OSU). His current responsibilities primarily include teaching courses and curriculum development for the FE program. Mr. Masud received his M.S. in Electrical Engineering from OSU in 2002, and received in B.S from Florida Institute of Technology in 1999.

STUART H. BRAND is an Instructional Lab Supervisor for the First-Year Engineering Program at The Ohio State University (OSU) College of Engineering. His current responsibilities include lab support, curriculum development, and educational multimedia development. He received his B.S. in Physics from OSU 1997, after serving as a submarine nuclear propulsion plant operator for the United States Navy.

MICHAEL J. HOFFMANN is an Instructional Laboratory Supervisor at The Ohio State University (OSU). Mr. Hoffmann is responsible for laboratory facilities within the First-Year Engineering Program, and develops laboratory experiments and instructional materials for the Program. He holds B.S. and M.S. degrees in Aeronautical and Astronautical Engineering from OSU.

ANITA P. AHUJA is Master of Science student in Industrial, Welding and Systems Engineering and a Graduate Teaching Associate for the First-Year Engineering Program at The Ohio State University. Her current responsibilities include curriculum development and assisting instructors. She also works as a Research Associate in the Industrial Engineering Department in the area of Six-Sigma Methodologies.

VAMSI K. IVATURI is a Graduate Teaching Associate for the First-Year Engineering Program at the Ohio State University (OSU) College of Engineering. He has actively contributed to the research and development of a Design-Build project for the First Year Engineering curriculum. His academic research interest is in the field of hardware design and verification.

"Proceedings of the 2003 American Society for Engineering Education Annual Conference \& Exposition Copyright (C) 2003, American Society for Engineering Education” 
Project Teams

\begin{tabular}{|c|c|c|c|c|c|c|c|c|c|c|c|c|}
\hline $\begin{array}{l}\text { ME/ISE } 682 \text { PROTOTYPE } \\
\text { EVALUATION }\end{array}$ & 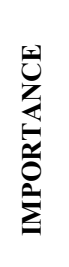 & 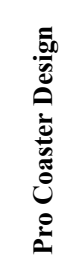 & 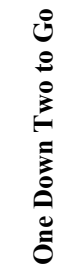 & $\sum_{0}^{\infty}$ & 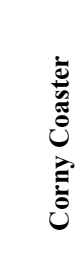 & 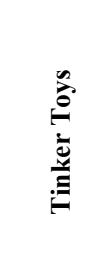 & 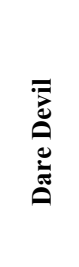 & 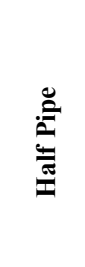 & 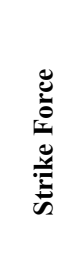 &  & $\stackrel{00}{\stackrel{0}{*}}$ & 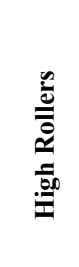 \\
\hline $\begin{array}{l}\text { Repeatably runs } 1 " \text { and } 3 / 4 " \\
\text { ball bearings through entire } \\
\text { track course (1-10 pts) }\end{array}$ & 25 & 10 & 6 & 6 & 10 & 7 & 10 & 6 & 5 & 10 & 8 & 10 \\
\hline $\begin{array}{l}\text { Demonstrates track features } \\
\text { (loops, 12" straight, bump, } \\
\text { etc) (1-10 pts) }\end{array}$ & 16 & 10 & 6 & 6 & 10 & 6 & 9 & 8 & 5 & 10 & 10 & 10 \\
\hline $\begin{array}{l}\text { Assembly and disassembly } \\
\text { time }\left(p t s=16-0.4^{*} \text { time }\right. \\
\text { where time is in minutes and } \\
0<=\text { pts }<=10 \text { ) }\end{array}$ & 12 & 18 & 10 & 30 & 28 & 30 & 15 & 6 & 5 & 2 & 15 & 10 \\
\hline $\begin{array}{l}\text { Ability to mass produce } \\
\text { (parts count, complexity, } \\
\text { cost) (1-10 pts) }\end{array}$ & 12 & 10 & 3 & 5 & 10 & 5 & 5 & 6 & 7 & 7 & 4 & 10 \\
\hline $\begin{array}{l}\text { Track configuration } \\
\text { flexibility (possible variability } \\
\text { in layouts) (1-10 pts) }\end{array}$ & 8 & 10 & 5 & 5 & 10 & 5 & 10 & 3 & 3 & 10 & 6 & 9 \\
\hline $\begin{array}{l}\text { Longevity and reuseablity of } \\
\text { parts (1-10 pts) }\end{array}$ & 8 & 6 & 5 & 5 & 10 & 10 & 10 & 10 & 10 & 9 & 10 & 10 \\
\hline Documentation (1-10 pts) & 8 & 10 & 9 & 10 & 9 & 7 & 10 & 9 & 7 & 7 & 8 & 10 \\
\hline $\begin{array}{l}\text { Disassembled coaster fits in } \\
\text { storage box (at least } 25 \\
\text { running feet; no more than } \\
25 \# \text { weight) (1-10 pts) }\end{array}$ & 8 & 7 & 10 & 10 & 10 & 10 & 10 & 7 & 10 & 10 & 10 & 10 \\
\hline $\begin{array}{l}\text { Sensor and Flag mounting } \\
\text { sites (1-10 pts) }\end{array}$ & 3 & 5 & 5 & 5 & 8 & 2 & 6 & 2 & 5 & 5 & 4 & 10 \\
\hline Totals & 100 & 91.46 & 64.90 & 60.90 & 92.36 & 64.10 & 91.20 & 70.80 & 66.40 & 91.70 & 81.20 & 99.20 \\
\hline & & \multicolumn{6}{|c|}{ 3:30 Session } & \multicolumn{5}{|c|}{ 5:30 Session } \\
\hline
\end{tabular}

Exhibit 1: Sample of Design Evaluation Worksheet (DEW), Winter 2003. 


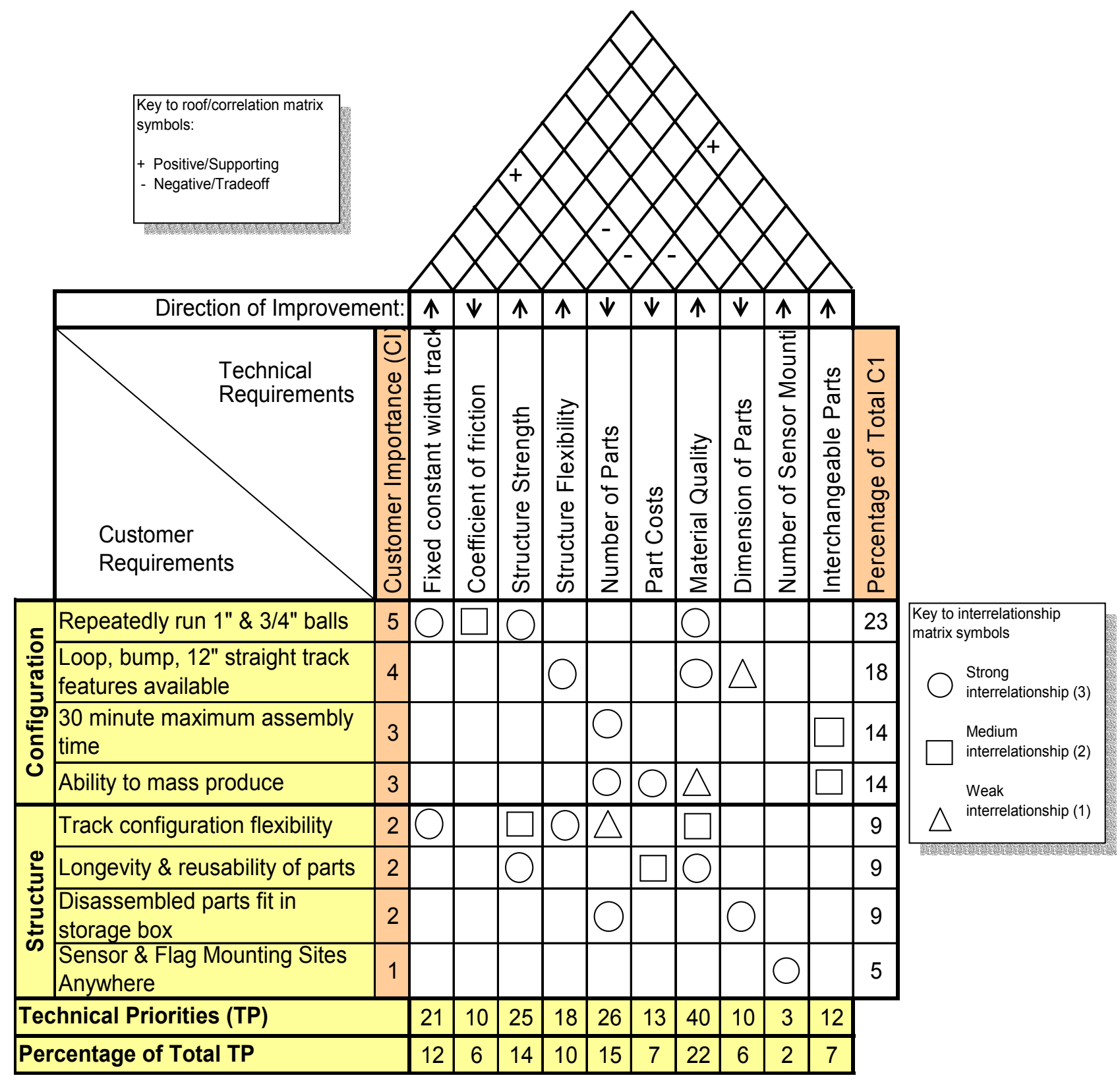

Exhibit 2: Sample House of Quality 

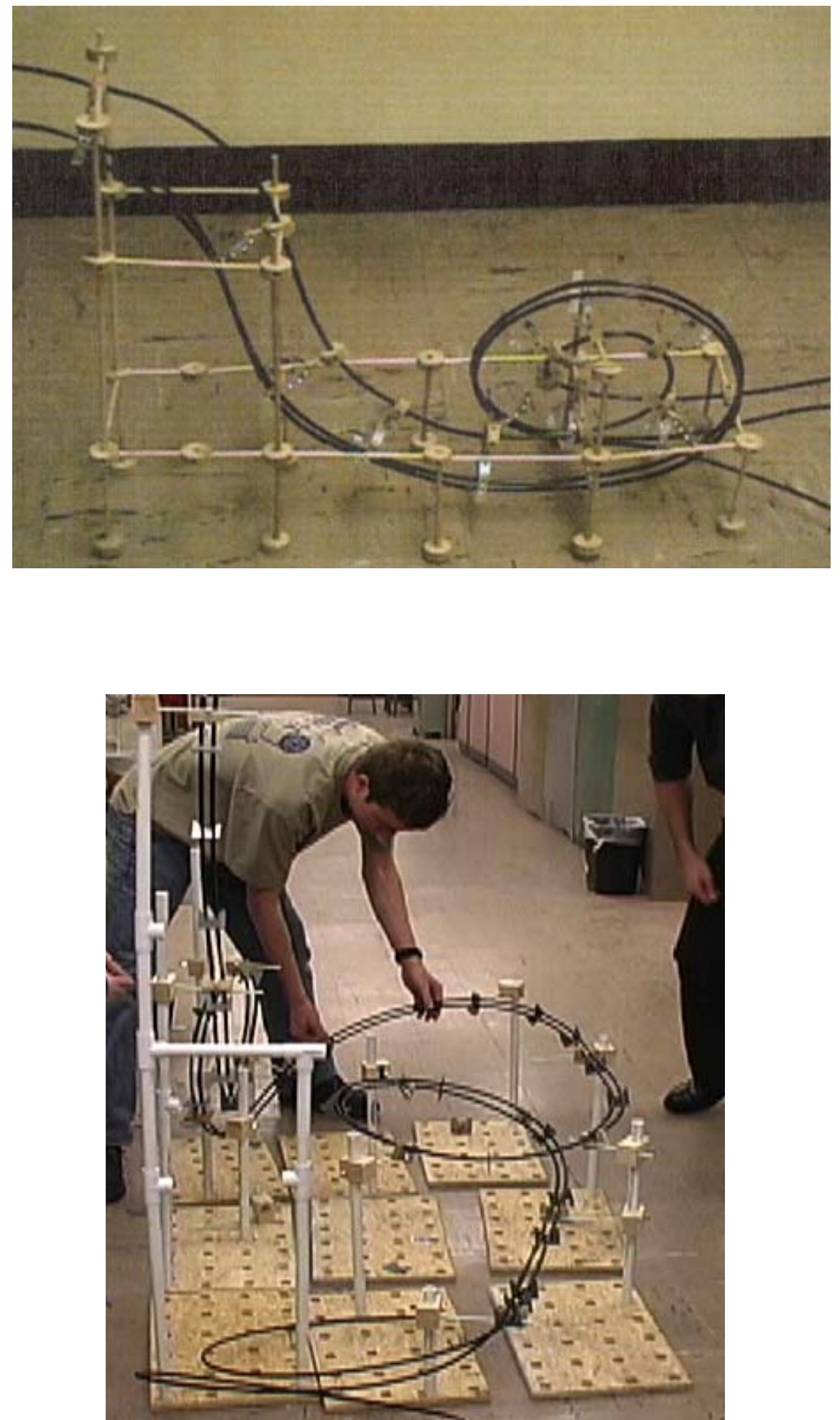

Exhibit 3: Student-Designed Track and Structure

"Proceedings of the 2003 American Society for Engineering Education Annual Conference \& Exposition Copyright (C) 2003, American Society for Engineering Education"” 

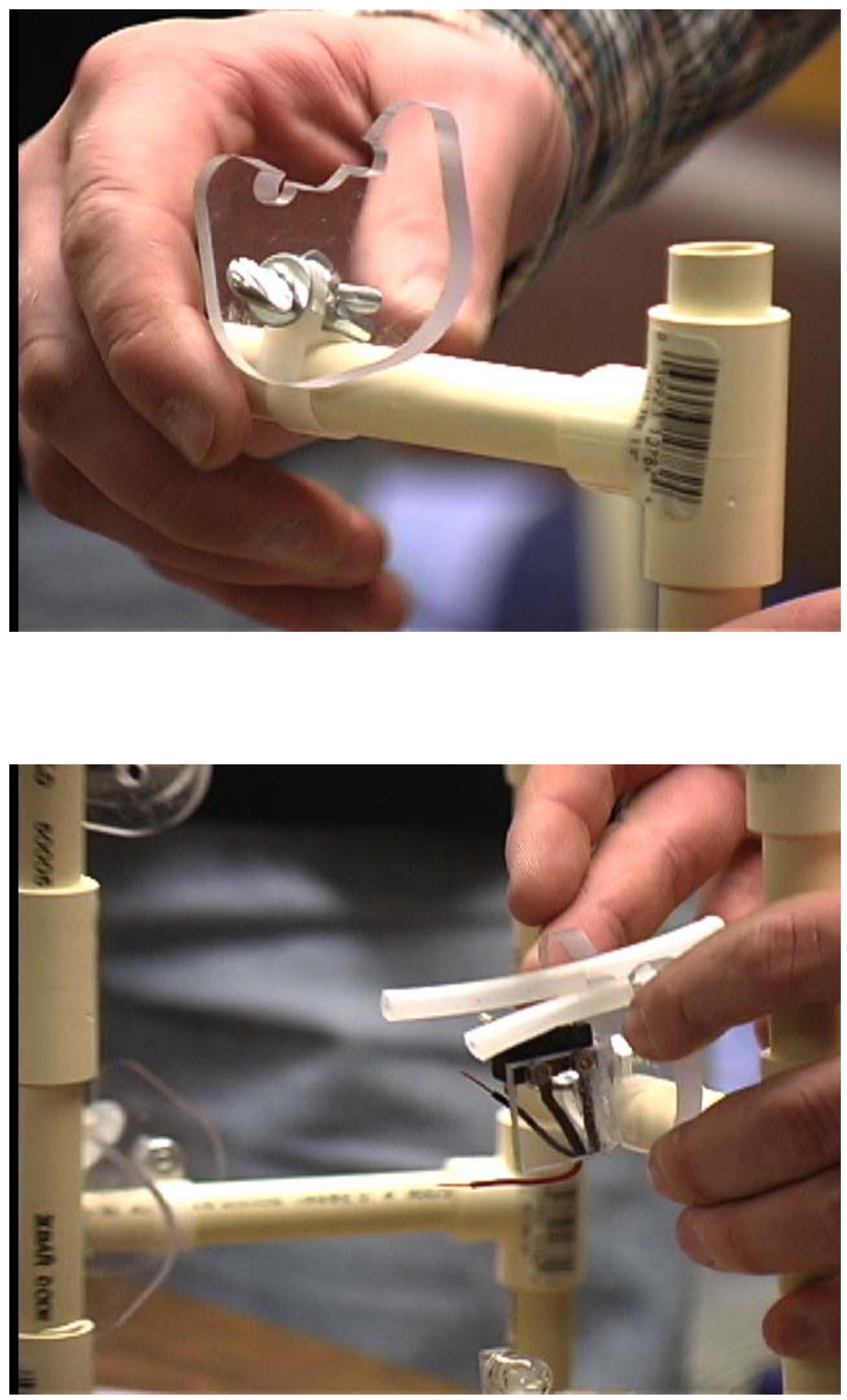

Exhibit 4: Student-Designed Mounting Bracket (for Track and Sensor) 